\title{
INTRAUTERINE VERSUS EXTERNAL TOCODYNAMOMETRY IN MONITORING LABOUR: A RANDOMISED CONTROLLED CLINICAL
}

\section{TRIAL}

Tuija Hautakangas, Head of Department, Delivery Ward, Department of Obstetrics and Gynecology, Central Hospital of Central Finland, Keskussairaalantie 19, 40620 Jyväskylä, Finland Jukka Uotila, Head of Obstetric Department, Department of Obstetrics and Gynecology, Tampere University Hospital and Faculty of Medicine and Health Technology, Tampere University, PL 2000, 33521 Tampere, Finland

Heini Huhtala, University Instructor, Faculty of Social Sciences, Tampere University, Arvo Ylpön katu 34, 33520 Tampere, Finland

Outi Palomäki, Assistant Head of Obstetric Department, Department of Obstetrics and Gynecology, Tampere University Hospital and Faculty of Medicine and Health Technology, Tampere University, PL 2000, 33521 Tampere, Finland

Correspondence to:

Tuija Hautakangas

Central Hospital of Central Finland,

Keskussairaalantie 19

40620 Jyväskylä

Finland

tuija.hautakangas@ksshp.fi

+358142695278

+358503393300

Running title: Intrauterine vs. external tocodynamometry: RCT 


\section{ABSTRACT}

\section{Objective}

To investigate whether the use of intrauterine vs. external tocodynamometry (IT vs. ET) during labour reduces operative deliveries and improves newborn outcome. As IT provides more accurate information on labour contractions, the hypothesis was that it may more appropriately guide oxytocin use than ET.

Design

Randomised controlled trial.

Setting

Two labour wards, in a university tertiary hospital and a central hospital.

Population

1504 parturients with singleton pregnancies, gestational age $\geq 37$ weeks and fetus in cephalic position: 269 women with uterine scars, 889 nulliparas and 346 parous women with oxytocin augmentation.

Methods

Participants underwent IT $(n=736)$ or ET $(n=768)$ during the active first stage of labour.

Main Outcome Measures

Primary outcome: rate of operative deliveries. Secondary outcomes: duration of labour, amount of oxytocin given, adverse neonatal outcomes.

Results 
Operative delivery rates were $26.9 \%$ (IT) and 25.9\% (ET) (OR 1.05, 95\% CI 0.84-1.32, $P=0.663$ ). The ET to IT conversion rate was $31 \%$. We found no differences in secondary outcomes (IT vs. ET). IT reduced oxytocin use during labours with signs of fetal distress, and TOLAC.

Conclusions

IT did not reduce the rate of operative deliveries, use of oxytocin, or adverse neonatal outcomes, and it did not shorten labour duration

\section{Funding}

Special Grant funding from the Government of Finland and the Finnish Cultural Foundation (ID: 00180293). Funding sources were not involved in collection, analysis or interpretation of data or writing the manuscript.

\section{Keywords}

Tocodynamometry, Contractions, Labour, Caesarean Section, Vacuum extraction, Intrauterine pressure catheter, TOLAC, VBAC, Oxytocin

\section{Trial registration}

Clinicaltrials.gov, identifier: NCT02941393, https://clinicaltrials.gov/ct2/results? cond $=\&$ term $=$ NCT02941393\& cntry $=\&$ state $=\&$ city $=\&$ dist $=$

\section{Tweetable abstract}

IT (vs. ET) reduced oxytocin use in high-risk labours but did not influence operative delivery rate or adverse neonatal outcomes. 


\begin{abstract}
Abbreviations
CS caesarean section

CTG cardiotocogram

ET external tocodynamometry

IOL induction of labour

IT internal tocodynamometry
\end{abstract}

IQR Interquartile range

IUPC intrauterine pressure catheter

MD Mean difference

NICU Neonatal Intensive Care Unit

RCT randomised controlled trial

TOLAC trial of labour after caesarean section

VE vacuum extraction

\title{
INTRODUCTION
}

A coordinated series of uterine contractions are necessary during labour to dilate the cervix and allow descent of the fetus down the birth canal. Intrauterine tocodynamometry (IT) provides quantitative information on the intensity and duration of contractions and the basal tone of the uterine muscle ${ }^{1}$. In clinical practice IT is often used in prolonged labour to aid in adjusting the dose of oxytocin, or if external tocodynamometry (ET) does not provide enough information. The use of IT is limited in cases of ruptured membranes. Although contractions of the uterus are essential for the progression of labour, excessive uterine activity can increase the risk of adverse fetal outcome $\mathrm{e}^{2,3}$. 
One large and three small randomised clinical trials of IT versus ET with respect to neonatal outcome and instrumental delivery rate have been published ${ }^{4-7}$. The study by Bakker et al. ${ }^{4}$ involved more than 1450 parturients, but the others ${ }^{5-7}$ were carried out over twenty years ago and included less than 250 patients. In these studies, oxytocin use, either for induction or augmentation, was the indication for inclusion, but women undergoing TOLAC (trial of labour after caesarean section) were excluded. In these study settings, no differences between the IT and ET groups were found. On the basis of three of these former studies ${ }^{4-6}$, a Cochrane meta-analysis confirmed that there was no benefit of IT over ET during induced or augmented labor ${ }^{8}$.

The aim of this randomised multi-centre clinical trial was to find out if the method of contraction monitoring in itself leads to different outcomes regarding the manner of delivery, oxytocin use or neonatal outcome. We presumed that having information on the power of contractions could influence the starting frequency or doses of oxytocin as well as the rate of operative deliveries. Neonatal outcome was studied as a secondary aim. This study is the first randomised controlled trial (RCT) concerning IT vs. ET and including parturients undergoing TOLAC. We included these parturients in our study to find out if this group would particularly benefit from the use of IT, as parturients who have experienced previous caesarean section (CS) have a $0.5-1.0 \%$ risk of uterine rupture during labor $^{9-11}$. Some clinical experts assume that with the use of IT the clinician would recognise uterine rupture earlier ${ }^{12}$.

\section{METHODS}


The study material was collected in two hospitals in Finland. First, from November 2012 in a university tertiary hospital with 5000 deliveries annually, and from July 2015 also in a central hospital with 2500 deliveries annually. Recruitment finished in December 2017 in both hospitals. The possibility to include recruitment of participants in the central hospital occurred after a change of workplace of the main investigator.

During the study period the overall CS rates, including elective CS, were $15 \%$ and $17 \%$ in the two study hospitals. Among nulliparas the overall CS rates were $18 \%$ and $20 \%$, and among TOLAC cases, $46 \%$ and $45 \%$. Oxytocin was used in $58 \%$ and $34 \%$ of all trials of labour in the study hospitals.

Recruitment of parturients took place either after spontaneous onset of labour in the labour ward or during induction of labour in the prenatal department. The participants were representatives of one of three subgroups: nulliparas, parous women with a clinical need of oxytocin augmentation during the first stage of labour, or parturients who had had a previous CS. Only parturients with singleton pregnancies, gestational age of at least 37 weeks and the fetus in cephalic position were recruited. Exclusion criteria were: cervical dilatation over $7 \mathrm{~cm}$; estimated birthweight $>4500 \mathrm{~g}$; positive results in serological tests for human immunodeficiency virus or hepatitis B or C virus; chorioamnionitis, or a non-reassuring fetal cardiotocogram (CTG) according to FIGO guidelines ${ }^{13}$ at randomisation. The participants received both oral and written information about the study and the process of randomisation. They entered the study voluntarily and were allowed to discontinue at any time.

\section{Randomisation, blinding and intervention}

After providing written consent, parturients at the active phase of labour were randomly assigned to have either an intrauterine pressure catheter (IUPC) or an external sensor for monitoring uterine contractions. Randomisation was performed at a 1:1 ratio by means of a computer program. 
Randomisation was carried out within the three subgroups mentioned above in order to avoid bias. A midwife at the labour ward opened a sealed envelope (numbered randomly) to determine the treatment group of the parturient. No amniotomies were carried out for the sake of the study alone, and if the progress of labour was fast without spontaneous rupture of membranes, the recruited woman left the study (all groups). Group assignments were not concealed from patients or physicians. Physicians were allowed to change the method of uterine monitoring if necessary for obstetric reasons.

Monitoring of labour followed hospital guidelines except that contraction monitoring followed the study protocol. A modified active management of labour protocol was used (maximum oxytocin dose $15 \mathrm{mIU} / \mathrm{min}$. If amniotomy was carried out, oxytocin administration for augmentation began one hour later if contractions did not start spontaneously. Oxytocin was administered by midwives in both groups in increasing doses, i.e. 2.0-2.5 IU/min addition every 20-30 minutes until 150-300 Montevideo units (IT group) or 3-5 contractions in ten minutes (ET group) were reached, or the progression of labour was adequate. In the IT group the basal tone of intrauterine pressure was guided in the direction of being under $20 \mathrm{mmHg}$ and relaxation of the uterus had to be seen between contractions. Antibiotics were used if sampling for Streptococcus agalactiae was positive or the parturient had signs of infection during labour. Tocolysis for intrauterine resuscitation with terbutaline was allowed in both groups in cases in which CTG pathology and/or tachysystole persisted after discontinuation of oxytocin.

In the IT group a sensor-tipped IUPC was used (Koala, Clinical Innovations) and it was inserted by a doctor during the first vaginal examination after randomisation. Possible difficulties with insertion were registered. External monitoring of contractions was carried out by using PHILIPS AVALON 
FM30 or FM 50 Gemini equipment. The IUPCs were connected to the same fetal monitors as the external sensors.

Basic data on the parturients and newborns were retrieved from the hospitals' medical files and electronic labour information systems. Detailed data were collected prospectively during and after birth in the labour ward, using a specific form created for the study. The first stage of labour was defined as the time from regular, painful contractions until the beginning of the second stage of labour. If the indication for intrapartum CS was fetal distress, the duration of labour was not recorded. Definitions for chorioamnionitis were intrapartum temperature more than $38.0{ }^{\circ} \mathrm{C}$ or a combination of fetal tachycardia and maternal C-reactive protein more than $20 \mathrm{~g} / 1$.

\section{Sample size}

Sample-size calculation was based on a 5\% expected reduction of operative deliveries in the IT group. To detect this difference with a power of $80 \%$ and a type I error of $5 \%$ we needed 2402 participants whose data could be analysed. Our goal was to have 2500 parturients in our study, while assuming a $4 \%$ rate of protocol violations.

An interim analysis of 1040 parturients was ready five years after beginning the study. Recruitment was continuing simultaneously while collecting and recording the data and analysing the results. The operative delivery rate in the IT group was $26.7 \%(n=136)$, and in the ET group, $25.6 \%(n=136),(O R$ $1.059 ; 95 \%$ CI $0.803-1.396, \mathrm{p}=0.685)$. Based on these numbers, the decision was made not to continue recruitment, as increasing the number of participants would not have changed the results regarding the primary endpoint.

\section{Outcome measures}


The primary outcome was the rate of operative deliveries, i.e. either CS or vacuum extraction (VE). Secondary outcomes included duration of labour, use of oxytocin during labour (number of parturients having oxytocin, total amount and maximum dose of oxytocin) and composite adverse neonatal outcome defined as Apgar scores $<7$ after 5 minutes, umbilical artery $\mathrm{pH}<7.05$ or admission to a Neonatal Intensive Care Unit (NICU).

Core outcome sets (COSs) did not exist at the time of designing this study, and a relevant COS still does not exist, or is in development at the time of submission.

\section{Statistical analysis}

Data were analysed according to the intention-to-treat principle. Further, analyses were carried out within randomisation subgroups and between those parturients who underwent the prescribed treatment and those cases where the treatment method was changed for obstetric reasons.

All statistical analyses were performed using SPSS for Windows 25 (IBM SPSS Statistics for Windows, Version 25.0. Armonk, NY: IBM Corp.). Continuous variables were expressed as means with standard deviations, or medians with ranges, depending on the shape of the distribution. When comparing continuous variables we used mean differences (MDs) with 95\% confidence intervals (95\% CI). Categorial variables were expressed in terms of frequencies and percentages. Comparisons between groups were performed by using the Mann-Whitney $U$-test, the Kruskal-Wallis test, Fisher's exact test or the chi-squared test, as appropriate. The results of logistic regression analyses were expressed as adjusted odds ratios (aORs) and 95\% CIs. A $P$-value of $<0.05$ was considered statistically significant. All $P$-values were two-sided.

\section{Patient and Public Involvement}


Patients were not involved in the development of the research, as this was not yet common at the time the study was planned. No participants were asked to take part in interpretation of the results. There are plans to disseminate the results of the study in annual meetings of obstetricians but not directly to study participants.

\section{Funding}

Financial support was received from Special Grant funding provided by the Government of Finland and the Finnish Cultural Foundation (grant identifier 00180293). Funding sources were not involved in the collection, analysis or interpretation of data, or writing of the manuscript.

\section{RESULTS}

1504 parturients participated in our study. Figure 1 shows a flowchart of the study groups and Table 1 the baseline characteristics of the study population. Table 2 shows labour outcome and Table 3 , neonatal outcome in the study groups. We found no difference in the rate of operative deliveries, or maximum doses and total oxytocin consumption between groups. Composite adverse neonatal outcomes did not differ between groups.

Signs of fetal distress influenced oxytocin use in the IT group, and both maximum dose and total amount of oxytocin were significantly lower than among labours without signs of distress (medians $7.5 \mathrm{IU} / \mathrm{min}$ vs. $10 \mathrm{IU} / \mathrm{min}$, and $2.0 \mathrm{IU}$ vs. $2.6 \mathrm{IU},(\mathrm{p}=0.027$ and 0.039 , respectively)). In the ET group signs of fetal distress did not affect oxytocin use (medians $10 \mathrm{IU} / \mathrm{min}$ and $2.5 \mathrm{IU}$ despite a diagnosis of fetal distress). Admission to a NICU among these cases of operative delivery with an indication of 
fetal distress was more frequent in the ET group (ET 26\% vs. IT 14\%; OR 2.14, 95\% CI 0.99-4.63, $P=0.051)$.

Difficulties with IUPC insertion were resistance $(n=33)$ and blood in the catheter during initial insertion $(\mathrm{n}=18)$. More than one attempt at insertion was needed in 51 cases. These difficulties did not increase the risks of adverse neonatal outcome or uterine rupture.

The majority of TOLAC parturients (78\%) succeeded in vaginal birth. Altogether, five clinically relevant (total) uterine ruptures occurred, all during TOLAC (four in the IT group and one in the ET group). Further, three large fenestrations with abnormal CTG findings and/or pain leading to CS were found.

Doctors were allowed to change the method of tocodynamometry if they considered the conversion clinically justifiable. In the IT group, an IUPC was not inserted in 22 parturients $(3.0 \%)$ because their labours progressed rapidly $(n=10)$ or because there were difficulties inserting the IUPC $(n=12)$. Expulsion of the IUPC occurred in 24 cases $(3.3 \%)$ in the IT group, usually during the second stage of labour. External monitoring of contractions was changed to IT in 241 cases (31.5\%). Unreliable ET, failure of progress, or need to monitor contractions more accurately because of suspicious CTG findings were mentioned as the main reasons for conversion given by clinicians. As changing the method of monitoring was common, we also analysed the main outcome measures according to the actual treatment received, i.e. per protocol. These analyses are shown in Tables 2 and 3 after the results in the intention-to-treat groups. In these secondary analyses the operative delivery rate was significantly higher in the IT group. Although the use of oxytocin was more frequent in the IT group, with higher doses and greater overall amounts, the indication for operative delivery was significantly 
more often failure to progress when IT was used. Conversely, fetal distress was less common as an indication for operative birth when IT was the actual method used. There were no differences in adverse outcomes of the neonates.

The outcomes were also analysed within randomisation subgroups (Table 4). The number of nulliparous parturients without oxytocin during the first stage of labour was minor in the IT group $(p=0.014)$ as was the total consumption of oxytocin in the IT TOLAC subgroup $(p=0.049)$. The second stage was shorter among parous women without TOLAC in the ET group. Additionally, in all IT subgroups we noticed a trend towards a lower amount of operative deliveries with an indication of fetal distress, and a higher amount with an indication of failure to progress, but these findings were not statistically significant.

\section{DISCUSSION}

\section{Main findings}

This randomised multi-centre study was designed to determine the effect of the method of monitoring labour contractions (i.e. IT vs. ET) on the rate of operative deliveries. We found no differences between the intention-to-treat groups, which is consistent with the results of previous randomised studies in this field ${ }^{4-7}$. In addition, the method of tocodynamometry did not have a significant influence on the duration of labour or on neonatal outcome.

Our initial hypothesis was that oxytocin use would be different according to the method used for tocodynamometry. The overall results do not support this. Nevertheless, there were two significant 
findings: IT guided clinicians towards reduced use of oxytocin in the TOLAC subgroup, and when operative delivery was indicated by fetal distress. In the whole IT group there was a trend towards a lower rate of operative deliveries with an indication of fetal distress, but as regards an indication of failure to progress, the trend was in the opposite direction. These findings may reflect the fact that the use of IT during labour could prevent excessive use of oxytocin among higher-risk cases, thus protecting the fetus from hyperstimulation of the uterus, and hypoxia. At the same time, this concern regarding the use of oxytocin could lead to failure to progress in labour.

The rationale concerning the possible beneficial effect of IT on labour outcome was based on the idea that guiding oxytocin treatment with the aid of IT could be "optimal" compared with that of ET. However, there are differing opinions concerning optimal oxytocin dosage and uterine activity. If the lowest effective dose of oxytocin is aimed at, uterine hyperstimulation may be avoided but the progress of labour may remain suboptimal, while an infusion rate aimed at giving maximal stimulation may lead to greater success in vaginal delivery at the cost of complications ${ }^{14-16}$. Thus, not only might IT per se affect treatment during labour, but it could also affect how the protocol is set regarding oxytocin dosage. We chose to administer oxytocin in the middle range of dosage guidelines, aiming at fairly rapid achievement of effective contractions, but without hyperstimulation. It is possible that with different targets of uterine stimulation, a difference in oxytocin dosage could also have been seen between groups. However, we consider that the protocol we chose was clinically relevant.

This study represents the first RCT carried out to compare ET and IT with inclusion of TOLAC. The number of uterine ruptures during TOLAC was high - twofold vs. those in other reports ${ }^{9-11}$. The use of IT did not prevent ruptures, as four out of five cases of total rupture were in the IT group. Thus, 
we cannot recommend the use of IT during TOLAC to prevent uterine ruptures. Sometimes uterine perforation might be even a consequence of IT. However, in our rupture cases there were no reports of difficulties in IUPC insertion and the ruptures occurred many hours later.

In contrast to earlier findings ${ }^{8}$, results in the per-protocol group were not similar to those in the intention-to-treat group: a change of ET to IT appeared to raise the rate of operative deliveries. Explanations can be found among indications for conversion - if conversion was from ET to IT the progress of labour was unsatisfactory or there were unclear decelerations in the CTG.

Regarding conversion, usually the change was from ET to IT, which was considerable. The high level of crossover led us to carry out a per-protocol analysis. The findings were interesting: the operative rate was higher in the IT group, although doctors probably had made the conversation in an attempt to avoid operative birth. Among IT-monitored births, indications of fetal distress were less frequent and indications of failure to progress were more frequent. In other words, probably the most challenging subgroup was the ET to IT conversion group, and although this did not help in avoiding operative delivery, the use of IT maybe helped clinicians to avoid distress-indicated operations. However, this did not affect neonatal outcome, which was found to be similar in both the intentionto-treat and per-protocol groups.

The use of oxytocin was frequent in our study population. This does not reflect the actual use of oxytocin in the two study hospitals, since one subgroup in our study consisted of parous women with clinical indications for oxytocin during labour $(n=347)$. It was also easier to recruit parturients when they had induction of labour (IOL) vs. women having painful contractions after spontaneous onset of 
labour. Parturients after IOL often need more oxytocin than those with spontaneous contractions. On the other hand, most of the fluent labours were excluded.

\section{Strengths and Limitations}

This is the largest RCT as regards participant numbers in this field so far. The strength of this prospective trial is that it reflects realistic clinical practice in our labour wards. Randomisation succeeded satisfactorily, as there were no significant differences in basic characteristics between groups. As the use and safety of IT vs. ET during TOLAC with our arrangement has not been studied before, this aspect has to be considered a strength of our study as well.

One weakness of our study was that recruitment of parturients took much longer than was presumed beforehand on the basis of the number of parturients in the study hospitals. The unique nature of giving birth was the most common reason to decline participation. In addition, in a hectic 24/7 action ward the activity of the staff as regards recruitment is not always a priority. Lack of blinding could also be counted as a limitation. We assume that the type of monitoring did not bias decision-making among obstetricians regarding the delivery route, and blinding would have been impossible when treating a parturient or analysing a CTG.

Patient involvement in study design as well as international efforts in developing uniform core outcome sets were not yet widely recognized when the study protocol was planned, and thus these aspects could not be used in this study. 


\section{Interpretation}

Two large RCTs (ours and one by Bakker et al., 20104) concerning IT versus ET during labour have revealed no benefit of IT as regards labour outcome. Therefore, there is no rationale for use of the IUPC method in labour treatment. Although IT is still recommended during slow progress of labor ${ }^{17}$, that recommendation is not based on evidence. Our results do not support this indication for IT use, failure to progress tending to be more common in the IT group. However, IT could be of benefit in cases of fetal distress, with fewer operative deliveries and reduced use of oxytocin in connection with this indication in the IT group. The results of these RCTs are economically important for labour hospitals, as each IUPC procedure brings costs. The use of IT also carries a risk of complications such as uterine perforation, extra-membranous placement, placental abruption, anaphylactoid syndrome, fetal vessel laceration and surgical-site infection post-CS ${ }^{18-22}$. Future studies might usefully be focused on new non-invasive methods such as electrohysterography ${ }^{23,24}$, as the need for sufficient knowledge concerning uterine contractions remains.

\section{CONCLUSIONS}

The use of intrauterine tocodynamometry does not diminish the rate of operative deliveries or improve neonatal outcome. The use of oxytocin did not differ between the IT and ET groups, but IT may guide clinicians to reduce oxytocin use during TOLAC or in cases of fetal distress.

Acknowledgements: We thank all the women who participated in this trial, and both participating institutions and their staff for their contribution to this study, particularly midwives and doctors for their excellent work. 


\section{Disclosure of Interests}

All authors have completed the ICMJE uniform disclosure form at www.icmje.org/coi_disclosure.pdf. TH has received research grants from Special Grant funding provided by the Government of Finland and the Finnish Cultural Foundation. OP reports personal fees as an obstetric educator from The Finnish Midwife Association, and as a consultant obstetrician for quality of care during conduction of the study. HH and JU have no disclosures.

There are no other relationships or activities that could appear to have influenced the submitted work.

\section{Contributors to Authorship}

TH contributed to the whole process: planning the study and the material for it, recruitment of parturients, collection of data, analysis of data and reporting the work and results.

$\mathrm{HH}$ contributed to analysis of the data and reporting the work and results.

JU contributed to the planning, conducting and reporting phases of the study.

OP provided the initial idea for the study structure and contributed to the planning, conducting and reporting phases of the work, and is an overall content guarantor.

The corresponding author attests that all listed authors meet authorship criteria and that no others meeting the criteria have been omitted.

\section{Details of Ethics Approval}

Ethics approval for the study was given by the Ethics Committee of Pirkanmaa Hospital District (R12229), in October 2012. 


\section{Funding}

Financial support was received from Special Grant funding provided by the Government of Finland and the Finnish Cultural Foundation (grant identifier 00180293). Funding sources have not been involved in the collection, analysis or interpretation of data or writing of the manuscript.

\section{Data sharing}

The full dataset is available from the corresponding author on reasonable request.

\section{References}

1. Caldeyro R, Alvarez R, Reynolds SRM. Better understanding of uterine contractility through simultaneous recording with an internal and a seven channel external method. Surg Gynecol Obstet. 1950;91:641-50.

2. Bakker PCAM, Kurver PHJ, Kuik DJ, Van Geijn HP. Elevated uterine activity increases the risk of fetal acidosis at birth. Am J Obstet Gynecol. 2007;196:313.e1-6. http://www.ncbi.nlm.nih.gov/pubmed/17403401

3. Simpson KR, James DC. Effects of oxytocin-induced uterine hyperstimulation during labor on fetal oxygen status and fetal heart rate patterns. Am J Obstet Gynecol. 2008;199.

4. Bakker JJH, Verhoeven CJM, Janssen PF, Van Lith JM, Van Oudgaarden ED, Bloemenkamp $\mathrm{KWM}$, et al. Outcomes after internal versus external tocodynamometry for monitoring labor. N Engl J Med. 2010;362:306-13.

5. Chia YT, Arulkumaran S, Soon SB, Norshida S, Ratnam SS. Induction of labour: does internal tocography result in better obstetric outcome than external tocography. Aust NZJ Obstet Gynaecol. 1993;33:159-61. http://www.ncbi.nlm.nih.gov/pubmed/8216115

6. Chua S, Kurup A, Arulkumaran S, Ratnam SS. Augmentation of labor: does internal tocography result in better obstetric outcome than external tocography? Obstet Gynecol. 1990;76:164-7. http://www.ncbi.nlm.nih.gov/pubmed/2196493

7. Panayotopoulos, N., Salamalekis, E., Vitoratos, N., Loghis, C., Kassanos D. Monitoring of uterine activity in cases of labor augmentation, and newborn outcome. Prenat Neonatal Med. 1998;3:464-7.

8. Bakker JJH, Janssen PF, van Halem K, van der Goes BY, Papatsonis DNM, van der Post JAM, et al. Internal versus external tocodynamometry during induced or augmented labour. Cochrane database Syst Rev. 2013;CD006947. http://www.ncbi.nlm.nih.gov/pubmed/23913521 
9. Tahseen S, Griffiths M. Vaginal birth after two caesarean sections (VBAC-2)-a systematic review with meta-analysis of success rate and adverse outcomes of VBAC-2 versus VBAC-1 and repeat (third) caesarean sections. Br J Obs Gynaecol. 2010;117:5-19.

10. Hofmeyr GJ, Say L, Gülmezoglu AM. WHO systematic review of maternal mortality and morbidity: The prevalence of uterine rupture. BJOG An Int J Obstet Gynaecol. 2005;112:1221-8.

11. Devarajan S, Talaulikar VS, Arulkumaran S. Vaginal birth after caesarean. Obstet Gynaecol Reprod Med. 2018;28:110-5. https://doi.org/10.1016/j.ogrm.2018.02.001

12. Vlemminx MWC, de Lau H, Oei SG. Tocogram characteristics of uterine rupture: a systematic review. Arch Gynecol Obstet. 2016;295:1-10.

13. FIGO News. Guidelines for the use of fetal monitoring. Int J Gynaecol Obstet. 1987;25:15967.

14. Arulkumaran S, Ingemarsson I, Ratnam SS. Oxytocin titration to achieve preset active contraction area values does not improve the outcome of induced labour. Br J Obs Gynaecol. 1987;94:242-8.

15. Bidgood KA, Steer PJ. A randomized control study of oxytocin augmentation of labour. I Obstetric outcome. Br J Obs Gynaecol. 1987;94:518-22.

16. Steer PJ, Carter MC, Choong K, Hanson M, Gordon AJ, Pkadhan P. A multicentre prospective randomized controlled trial of induction of labour with an automatic closed-loop feedback controlled oxytocin infusion system. BJOG An Int J Obstet Gynaecol. 1985;92:1127-33.

17. Rhoades JS, Cahill AG. Defining and Managing Normal and Abnormal First Stage of Labor. Obstet Gynecol Clin North Am. 2017;44:535-45.

18. Rood KM. Complications Associated with Insertion of Intrauterine Pressure Catheters: An Unusual Case of Uterine Hypertonicity and Uterine Perforation Resulting in Fetal Distress after Insertion of an Intrauterine Pressure Catheter. Case Rep Obstet Gynecol. 2012;2012:13.

19. Wilmink FA, Wilms FF, Heydanus R, Mol BWJ, Papatsonis DNM. Fetal complications after placement of an intrauterine pressure catheter: A report of two cases and review of the literature. J Matern Neonatal Med. 2008;21:880-3.

20. Harbison L, Bell L. Anaphylactoid syndrome after intrauterine pressure catheter placement. Obstet Gynecol. 2010;115:407-8.

21. Mirza FG, Thaker HM, Flejter WL, D'Alton ME. Fetomaternal Hemorrhage following Placement of an Intrauterine Pressure Catheter: Report of a New Association. Case Rep Obstet Gynecol. 2015;2015:1-3. http://www.hindawi.com/journals/criog/2015/348279/

22. Gee SE, Ma'ayeh M, Ward C, Buhimschi C, Klebanoff M, Rood K. Intrauterine Pressure Catheter Use Is Associated with an Increased Risk of Postcesarean Surgical Site Infections. Am J Perinatol. 2020;37:557-61.

23. Vlemminx MWC, Rabotti C, Van Der Hout-Van Der Jagt MB, Oei SG. Clinical Use of Electrohysterography during Term Labor: A Systematic Review on Diagnostic Value, 
Advantages, and Limitations. Obstet Gynecol Surv. 2018;73:303-24.

24. Euliano TY, Nguyen MT, Darmanjian S, McGorray SP, Euliano N, Onkala A, et al. Monitoring uterine activity during labor: A comparison of 3 methods. Am J Obstet Gynecol. 2013;208:66.e1-66.e6. http://dx.doi.org/10.1016/j.ajog.2012.10.873

\section{Table/Figure Caption List}

Figure 1. Flowchart of the study population.

Table 1. Baseline characteristics of the study population.

Table 2. Labour outcome in the study groups.

Table 3. Neonatal outcome in the study groups.

Table 4. Labour outcome within randomisation subgroups. 
Table 1. Baseline characteristics of the study population.

\begin{tabular}{|c|c|c|c|c|}
\hline \multirow[b]{2}{*}{ Characteristic } & \multicolumn{2}{|c|}{ IT $n=736$} & \multicolumn{2}{|c|}{ ET $n=768$} \\
\hline & $\begin{array}{l}\text { n/mean/ } \\
\text { median }\end{array}$ & $\% / S D / I Q R$ & $\begin{array}{l}\text { n/mean/ } \\
\text { median }\end{array}$ & $\% \mathrm{SD} / / \mathrm{IQR}$ \\
\hline Nulliparous & 439 & 59.6 & 449 & 58.5 \\
\hline Parous women augmented (TOLAC excluded ) & 165 & 22.4 & 182 & 23.7 \\
\hline TOLAC & 132 & 17.9 & 137 & 17.8 \\
\hline Maternal age (years) & 29.4 & 5.1 & 29.3 & 5.4 \\
\hline Maternal height (meters) & 1.66 & 0.06 & 1.66 & 0.06 \\
\hline BMI before pregnancy $\left(\mathrm{kg} / \mathrm{m}^{2}\right)$ & 24.8 & $22.1-29.3$ & 24.6 & $21.8-28.9$ \\
\hline Any diabetes & 177 & 23.9 & 189 & 24.7 \\
\hline Gestational age (days) & 281.0 & $275-288$ & 280.6 & $273-288$ \\
\hline Streptococcus agalactiae-positive * & 157 & 23.8 & 129 & 18.6 \\
\hline Induction of labour by prostaglandin or/and Foley catheter & 183 & 24.9 & 206 & 26.8 \\
\hline Induction of labour by amniotomy or/and oxytocin & 227 & 30.8 & 218 & 28.4 \\
\hline Cervical dilatation at the time of randomization $(\mathrm{cm})$ & 3.69 & $3.0-4.0$ & 3.61 & $3.0-4.0$ \\
\hline
\end{tabular}

$\mathrm{IT}=$ internal tocodynamometry; $\mathrm{ET}=$ external tocodynamometry; $\mathrm{IQR}=$ Interquartile range; $\mathrm{BMI}=$ Body mass index; TOLAC=trial of labour after caesarean section $* P<0.001$

Table 2. Labour outcome in the study groups.

\begin{tabular}{|c|c|c|c|c|c|c|c|}
\hline \multirow[b]{2}{*}{ Outcome/related factors (intention to treat) } & \multicolumn{2}{|c|}{ IT $n=736$} & \multicolumn{2}{|c|}{ ET $n=768$} & \multirow[b]{2}{*}{$\mathrm{OR} /(\mathrm{MD})$} & \multirow[b]{2}{*}{$95 \% \mathrm{CI}$} & \multirow[b]{2}{*}{$P$-value } \\
\hline & $\begin{array}{l}\text { n/mean/ } \\
\text { median }\end{array}$ & $\begin{array}{c}\text { \%/SD/ } \\
\text { IQR }\end{array}$ & $\begin{array}{l}\text { n/mean/ } \\
\text { median }\end{array}$ & $\begin{array}{c}\% / \mathrm{SD} / \\
\mathrm{IQR}\end{array}$ & & & \\
\hline Any operative delivery* & 198 & 26.9 & 199 & 25.9 & 1.05 & $0.84-1.32$ & 0.663 \\
\hline Caesarean section & 99 & 13.5 & 101 & 13.2 & 1.03 & $0.76-1.38$ & 0.864 \\
\hline Vacuum extraction & 99 & 13.5 & 98 & 12.8 & 1.06 & $0.89-1.43$ & 0.691 \\
\hline \multicolumn{8}{|l|}{ Indications for any operative delivery } \\
\hline Fetal distress & 78 & $39.6^{\dagger}$ & 104 & $52.8 \dagger$ & 0.76 & $0.55-1.04$ & 0.080 \\
\hline Failure to progress & 72 & $36.5+$ & 55 & $27.1 \dagger$ & 1.41 & $0.97-2.03$ & 0.068 \\
\hline Other indication & 47 & $23.9^{\dagger}$ & 40 & $20.1+$ & 1.24 & $0.80-1.92$ & 0.328 \\
\hline Duration of stage I, minutes & 904 & $508-1372$ & 907 & $508-1413$ & $(-12.8)$ & $-84.9-59.4$ & 0.729 \\
\hline Duration of stage II, minutes & 21.0 & $12-38$ & 21.0 & $11-39$ & $(0.17)$ & $-3.06-3.40$ & 0.822 \\
\hline Minutes from rupture of membranes to delivery & 419 & $206-910$ & 407 & $207-890$ & $(-116)$ & $-219--12.7$ & 0.659 \\
\hline $\begin{array}{l}\text { Oxytocin augmentation in the first stage of } \\
\text { labour }\end{array}$ & 656 & 89.1 & 665 & 86.6 & 1.27 & $0.93-1.73$ & 0.132 \\
\hline Oxytocin maximum dose, $\mathrm{mIU} / \mathrm{min}$ & 10.0 & $6-15$ & 10.0 & $6-15$ & $(-0.18)$ & $-0.90-0.55$ & 0.808 \\
\hline Oxytocin total consumption IU $\ddagger$ & 2.5 & $1.0-5.0$ & 2.5 & $1.0-5.0$ & $(-0.10)$ & $-0.44-0.25$ & 0.972 \\
\hline Fetal scalp blood sampling & 81 & 11.0 & 92 & 12.0 & 0.91 & $0.66-1.25$ & 0.554 \\
\hline Fetal scalp blood sampling $\mathrm{pH}$ & 7.29 & 0.06 & 7.27 & 0.06 & $(-0.03)$ & $-0.05--0.01$ & 0.009 \\
\hline
\end{tabular}




\begin{tabular}{|c|c|c|c|c|c|c|c|}
\hline Clinical chorioamnionitis & 78 & 10.6 & 83 & 10.8 & 0.98 & $0.71-1.36$ & 0.896 \\
\hline Meconium-stained amniotic fluid & 125 & 18.1 & 134 & 18.8 & 0.95 & $0.73-1.25$ & 0.734 \\
\hline Tocolysis for intrauterine resuscitation & 40 & 5.9 & 37 & 5.2 & 1.14 & $0.72-1.80$ & 0.587 \\
\hline Postpartum haemorrhage, $\mathrm{ml}$ & 400 & $300-600$ & 400 & $300-588$ & $(-9.4)$ & $-53.7-35.0$ & 0.670 \\
\hline Uterine rupture & 4 & 0.5 & 1 & 0.1 & 4.19 & $0.47-37.6$ & 0.209 \\
\hline Uterine fenestration & 2 & 0.3 & 1 & 0.1 & 2.09 & $0.19-23.1$ & 0.617 \\
\hline & \multicolumn{2}{|c|}{ IT $\mathbf{n}=927$} & \multicolumn{2}{|c|}{$\mathbf{E T} \mathbf{n}=\mathbf{5 7 7}$} & \multirow[b]{2}{*}{ OR(/MD) } & \multirow[b]{2}{*}{$95 \% \mathrm{CI}$} & \multirow[b]{2}{*}{$P$-value } \\
\hline According to treatment received/per protocol & n/median & $\% / I Q R$ & n/median & $\% / I Q R$ & & & \\
\hline \multirow{2}{*}{ Any operative delivery* } & 299 & 32.3 & 98 & 17.0 & 2.33 & $1.80-3.0$ & $<0.001$ \\
\hline & & & & & \multicolumn{3}{|c|}{1} \\
\hline Vacuum extraction & 138 & 14.9 & 59 & 10.2 & 1.54 & $1.11-2.12$ & 0.009 \\
\hline Caesarean section & 161 & 17.3 & 39 & 6.8 & 2.90 & $2.01-4.18$ & $<0.001$ \\
\hline Indication fetal distress & 125 & 42.1 & 57 & 58.8 & 1.42 & $1.02-1.98$ & 0.037 \\
\hline Indication failure to progress & 109 & 36.6 & 18 & 18.6 & 4.14 & $2.49-6.89$ & $<0.001$ \\
\hline Oxytocin augmentation in the first stage of & 853 & 92.0 & 468 & 81.1 & 2.69 & $1.96-3.68$ & $<0.001$ \\
\hline \multicolumn{8}{|l|}{ labour } \\
\hline Oxytocin maximum dose, $\mathrm{mIU} / \mathrm{min}$ & 10 & $7.5-15.0$ & 10 & $5.0-15.0$ & $(-2.29)$ & $-3.03--1.55$ & $<0.001$ \\
\hline Oxytocin total consumption IU $\ddagger$ & 3.0 & $1.2-5.0$ & 2.0 & $0.6-4.0$ & $(-1.26)$ & $-1.61--0.91$ & $<0.001$ \\
\hline
\end{tabular}

$\mathrm{IT}=$ internal tocodynamometry; $\mathrm{ET}=$ external tocodynamometry; $\mathrm{IQR}=$ Interquartile range; $\mathrm{MD}=$ Mean difference; $\mathrm{BMI}=$ Body mass index; TOLAC= trial of labour after caesarean section

*caesarean section or vacuum extraction, ${ }^{\dagger}$ percentage of operative deliveries, $¥ 293$ missing values

Table 3. Neonatal outcome in the study groups.

\begin{tabular}{|c|c|c|c|c|c|c|c|}
\hline \multirow[b]{2}{*}{$\begin{array}{l}\text { Outcome/related factors (intention to } \\
\text { treat) }\end{array}$} & \multicolumn{2}{|c|}{ IT $n=736$} & \multicolumn{2}{|c|}{ ET $n=768$} & \multirow[b]{2}{*}{ OR/(MD) } & \multirow[b]{2}{*}{$95 \% \mathrm{CI}$} & \multirow[b]{2}{*}{$P$-value } \\
\hline & $\mathbf{n} /$ mean & $\% /$ SD & n/mean & $\% /$ SD & & & \\
\hline Composite adverse neonatal outcome* & 97 & 13.2 & 100 & 13.0 & 1.01 & $0.75-1.37$ & 0.927 \\
\hline Apgar score $<7$ at $5 \mathrm{~min}$ & 11 & 1.5 & 15 & 2.0 & 0.76 & $0.35-1.67$ & 0.495 \\
\hline Umbilical artery $\mathrm{pH}<7.05$ & 12 & 1.6 & 7 & 0.9 & 1.80 & $0.71-4.60$ & 0.212 \\
\hline Admission to NICU & 87 & 11.9 & 93 & 12.1 & 0.97 & $0.71-1.33$ & 0.863 \\
\hline Apgar score, 1 minute & 8.30 & 1.27 & 8.33 & 1.25 & $(0.03)$ & $-0.10-0.16$ & 0.625 \\
\hline Apgar score $<7$ at $1 \mathrm{~min}$ & 50 & 6.8 & 52 & 6.8 & 1.00 & $0.67-1.50$ & 0.986 \\
\hline Apgar score, 5 minutes & 8.81 & 0.72 & 8.83 & 0.67 & $(0.02)$ & $-0.05-0.09$ & 0.562 \\
\hline Umbilical artery $\mathrm{pH}$ & 7.23 & 0.09 & 7.23 & 0.09 & $(0.001)$ & $-0.008-0.01$ & 0.748 \\
\hline Umbilical artery $\mathrm{pH}<7.15$ & 103 & 14.0 & 115 & 15.0 & 0.92 & $0.69-1.23$ & 0.590 \\
\hline Umbilical vein $\mathrm{pH}$ & 7.31 & 0.08 & 7.31 & 0.08 & 0.007 & $-0.02-0.01$ & 0.610 \\
\hline Antibiotic treatment $\dagger$ & 51 & 7.9 & 52 & 7.7 & 1.03 & $0.69-1.53$ & 0.904 \\
\hline Birthweight, grams & 3660 & 462 & 3634 & 460 & $(-26.3)$ & $-72.9-20.4$ & 0.271 \\
\hline
\end{tabular}




\begin{tabular}{|c|c|c|c|c|c|c|c|}
\hline \multirow[b]{2}{*}{$\begin{array}{l}\text { Outcome according to treatment } \\
\text { received (per protocol) }\end{array}$} & \multicolumn{2}{|c|}{ IT $\mathbf{n}=927$} & \multicolumn{2}{|c|}{ ET $\mathbf{n}=\mathbf{5 7 7}$} & \multirow[b]{2}{*}{$\mathrm{OR} /(\mathrm{MD})$} & \multirow[b]{2}{*}{$95 \%$ CI } & \multirow[b]{2}{*}{$P$-value } \\
\hline & n/mean & $\% / \mathrm{SD}$ & n/mean & $\% /$ SD & & & \\
\hline Composite adverse neonatal outcome* & 130 & 14.0 & 67 & 11.6 & 1.24 & $0.91-1.70$ & 0.178 \\
\hline Apgar score $<7$ at $5 \mathrm{~min}$ & 17 & 1.8 & 9 & 1.6 & 1.18 & $0.52-2.66$ & 0.692 \\
\hline Umbilical artery $\mathrm{pH}<7.05$ & 12 & 1.3 & 7 & 1.2 & 1.07 & $0.42-2.73$ & 0.891 \\
\hline Admission to NICU & 120 & 12.9 & 60 & 10.4 & 1.28 & $0.92-1.78$ & 0.139 \\
\hline Antibiotic treatment ${ }^{\dagger}$ & 65 & 7.0 & 38 & 6.6 & 1.05 & $0.69-1.59$ & 0.609 \\
\hline
\end{tabular}

IT=internal tocodynamometry; ET= external tocodynamometry; MD=Mean difference; NICU= Neonatal Intensive Care Unit

*Apgar scores $<7$ after 5 minutes, umbilical artery $\mathrm{pH}<7.05$ or admission to a NICU, $\dagger_{180}$ missing values

Table 4. Labour outcome in randomisation subgroups.

\begin{tabular}{|c|c|c|c|c|c|c|c|c|c|c|c|c|c|c|c|}
\hline & \multicolumn{5}{|c|}{ Nulliparous $(n=889)$} & \multicolumn{5}{|c|}{ Parous women excl. TOLAC $(n=346)$} & \multicolumn{5}{|c|}{ TOLAC $(n=269)$} \\
\hline & \multicolumn{2}{|c|}{ IT $n=439$} & \multicolumn{2}{|c|}{ ET $n=450$} & \multirow[b]{2}{*}{$\begin{array}{c}P \text { - } \\
\text { value }\end{array}$} & \multicolumn{2}{|c|}{ IT $n=165$} & \multicolumn{2}{|c|}{ ET $n=182$} & \multirow[b]{2}{*}{$\begin{array}{c}P \text { - } \\
\text { value }\end{array}$} & \multicolumn{2}{|c|}{ IT $n=132$} & \multicolumn{2}{|c|}{ ET $n=137$} & \multirow[b]{2}{*}{$\begin{array}{c}P \text { - } \\
\text { value }\end{array}$} \\
\hline & $\begin{array}{c}\mathbf{n} / \\
\text { median }\end{array}$ & $\begin{array}{c}\% / \\
\text { IQR }\end{array}$ & $\begin{array}{c}\mathbf{n} / \\
\text { median }\end{array}$ & $\begin{array}{c}\% / \\
\text { IQR }\end{array}$ & & $\begin{array}{c}\mathbf{n} / \\
\text { median }\end{array}$ & $\begin{array}{c}\% / \\
\text { IQR }\end{array}$ & $\begin{array}{c}\mathbf{n} / \\
\text { median }\end{array}$ & $\begin{array}{c}\% / \\
\text { IQR }\end{array}$ & & $\begin{array}{c}\mathbf{n} / \\
\text { median }\end{array}$ & $\begin{array}{c}\% \\
/ I Q R\end{array}$ & $\begin{array}{c}\mathbf{n} / \\
\text { median }\end{array}$ & $\begin{array}{c}\% \\
/ I Q R\end{array}$ & \\
\hline $\begin{array}{l}\text { Operative } \\
\text { delivery }\end{array}$ & 143 & $32 . .6$ & 137 & 30.4 & 0.494 & 10 & 6.1 & 10 & 5.5 & 0.831 & 44 & 33.3 & 52 & 38.0 & 0.429 \\
\hline $\begin{array}{r}\text { Caesarean } \\
\text { section }\end{array}$ & 64 & 14.6 & 64 & 14.2 & 0.880 & 6 & 3.6 & 7 & 3.9 & 0.910 & 29 & 22.0 & 30 & 21.9 & 0.989 \\
\hline $\begin{array}{r}\text { Vacuum } \\
\text { extraction }\end{array}$ & 79 & 18.0 & 73 & 16.2 & 0.483 & 4 & 2.4 & 3 & 1.7 & 0.613 & 16 & 12.1 & 22 & 16.1 & 0.354 \\
\hline $\begin{array}{l}\text { Indication for } \\
\mathrm{CS} / \mathrm{VE}\end{array}$ & & & & & & & & & & & & & & & \\
\hline Fetal distress & 45 & 10.3 & 57 & 12.7 & 0.258 & 5 & 3.0 & 6 & 3.3 & 0.880 & 17 & 12.9 & 24 & 17.5 & 0.290 \\
\hline $\begin{array}{r}\text { Failure to } \\
\text { progress }\end{array}$ & 56 & 12.8 & 44 & 9.8 & 0.160 & 2 & 1.2 & 1 & 0.6 & 0.607 & 14 & 10.6 & 10 & 7.3 & 0.342 \\
\hline $\begin{array}{l}\text { Composite } \\
\text { adverse } \\
\text { neonatal } \\
\text { outcome }\end{array}$ & 74 & 16.9 & 71 & 15.8 & 0.663 & 12 & 7.3 & 11 & 6.1 & 0.656 & 11 & 8.3 & 18 & 13.1 & 0.204 \\
\hline $\begin{array}{l}\text { Duration of } \\
\text { stage I, min }\end{array}$ & 1110 & $\begin{array}{l}737- \\
1604\end{array}$ & 1124 & $\begin{array}{l}800- \\
1600\end{array}$ & 0.676 & 355 & $\begin{array}{l}225- \\
630\end{array}$ & 409 & $\begin{array}{l}256- \\
655\end{array}$ & 0.175 & 829 & $\begin{array}{l}540- \\
1300\end{array}$ & 802 & $\begin{array}{l}510- \\
1310\end{array}$ & 0.702 \\
\hline $\begin{array}{l}\text { Duration of } \\
\text { stage II, min }\end{array}$ & 27 & $17-46$ & 30 & $\begin{array}{l}18- \\
47\end{array}$ & 0.241 & 10 & $6-17$ & 9 & $5-13$ & 0.014 & 20 & $\begin{array}{l}12- \\
36\end{array}$ & 21 & $13-29$ & 0.876 \\
\hline $\begin{array}{l}\text { Without } \\
\text { oxytocin in } \\
\text { stage I }\end{array}$ & 49 & 11.2 & 76 & 16.9 & 0.014 & 0 & 0 & 0 & 0 & NS & 21 & 15.9 & 13 & 9.5 & 0.113 \\
\hline $\begin{array}{c}\text { Maximum } \\
\text { dose, } \mathrm{mIU} / \mathrm{min}\end{array}$ & 12.5 & $\begin{array}{l}7.5- \\
17.5\end{array}$ & 11.5 & 10 & 0.569 & 10 & $\begin{array}{l}7.5- \\
15\end{array}$ & 10 & 7.5 & 0.861 & 10 & $\begin{array}{c}7.5- \\
15\end{array}$ & 10 & 7.5 & 0.109 \\
\hline $\begin{array}{l}\text { Total } \\
\text { consumption, } \\
\text { IU }\end{array}$ & 3.0 & $\begin{array}{l}2.0- \\
5.0\end{array}$ & 3.0 & $\begin{array}{l}2.0- \\
5.0\end{array}$ & 0.306 & 2.5 & $\begin{array}{l}1.4- \\
4.6\end{array}$ & 2.5 & $\begin{array}{l}1.0- \\
4.0\end{array}$ & 0.532 & 2.0 & $\begin{array}{l}1.0- \\
4.5\end{array}$ & 3.0 & $1.9-5.0$ & 0.049 \\
\hline
\end{tabular}

IT=internal tocodynamometry; ET=external tocodynamometry; IQR=Interquartile range; TOLAC=trial of labour after caesarean section; $\mathrm{CS}=$ Caesarean section; $\mathrm{VE}=$ Vacuum extraction 